Bronchial Mucocoele and Endobronchial Tumours

SIR,-In your leading article "Bronchial Mucocoele" (25 September, p. 721) it is suggested that these lesions need not be resected and that "more conservative management might be considered." The question of the production of a mucocoele distal to an endobronchial block produced by an endobronchial tumour (adenoma or carcinoma) was not even considered, despite this probably being the most common cause of this appearance.

Chandler ${ }^{1}$ noted that endobronchial tumours would produce secondary bronchiectasis and cause retained secretions in the bronchi. It is a common finding at bronchoscopy for there to be retained secretions behind an obstruction in a large bronchus, and this is also common in surgical and necropsy specimens.

Relatively early diagnosis of bronchial carcinoma depends on the recognition of the possibility of this condition before an obvious large mass lesion is seen on a radiograph or there is gross collapse or consolidation distal to an endobronchial tumour. Such a tumour, which may not have given rise to metastases, may cause the development of mucocoeles and/or bronchiectasis with fluid-filled bronchi within a still aerated lung parenchyma. In a recent study $I$ found this sign to be present in 9 out of 400 cases on plain radiographs or tomograms. In some cases the mucocoele was small and in others very large. The presence of a mucocoele was described as a new sign of bronchial neoplasm by Rees and Ruttley. ${ }^{2}$ If the presence of an underlying neoplasm is not considered in any particular patient the chance of curative surgery may well be missed.-I am, etc.,

F. W. WRIGHT

Churchill Hospital,

Headington, Oxford

1 Chandler, F. G., British fournal of Radiology, 1932, 5, 721 .

Rees, D. O., and Ruttley, M. S. T., Clinical Radiology, 1970, 21, 62.

\section{Multiple Sclerosis in South Africa}

SIR,-The studies reported by Dr. G. Dean and Professor J. F. Kurtzke (25 September, p. 725) show that the incidence of multiple sclerosis in those emigrating from Northern Europe to South Africa was much lower among those who arrived in that country before the age of 16 years than in those who arrived at a later age, and these authors stress the need for a complementary study of immigrants from a low risk to a high risk area. Such information is, I think, provided by the remarkable study by Leibowitz et al.,1 who reported that among children born in Israel those of Afro-Asian and those of European origin have the same prevalence rates-a state of affairs which is in sharp contrast to the situation as regards the immigrants themselves. These writers conclude that their findings "lend further support to the hypothesis that environmental factors play a role in the aetiology of multiple sclerosis." It may be pointed out that the South African studies are also compatible with this hypothesis, on the basis that if you absorb the South African white man's way of life before you are 16 years of age, then you acquire much of the protec- tion which South African born whites enjoy. -I am, etc.,

W. RITCHIE RUSSELI Oxford

1 Leibowitz, U., Kahana, E., and Alter, M., Lancet, $1969,2,1323$.

\section{Doctor in the Lab}

SIR,-Your leading article "Doctor in the Lab" (25 September, p. 719) has missed the central issue with regard to laboratory medicine's future. In its training schemes the Royal College of Pathologists is still looking backwards to the halcyon days before the specialty was split up, and is still insisting that all pathologists have a smattering of every branch of the subject. Historically, in sentiment, and often geographically the branches of pathology are indeed closely linked, but there can be no doubt that the fundamental professional relationships are not between pathologist and pathologist, but between pathologist and clinician.

At a time when few pathologists will have to oversee more than one discipline, when there are in our laboratories an increasing number of scientists who are better qualified and better fitted to supervise the technical work, and especially at a time when there is a tendency to slot a man of 25 or so into the "career structure" of a specialty and make it difficult for him to change, at this time it is imperative that new training schemes should be devised that will link each specialty in pathology to its related clinical departments. Thus training for microbiology would involve time in infectious diseases, general surgery, general practice, and public health instead of in morbid anatomy, histopathology, clinical chemistry, and haematology. Moreover, there must be more movement (without loss of seniority) between pathological and related clinical specialties at an advanced stage of training. It must be realized that the resulting crossfertilization of ideas and outlook would far outweigh any disadvantages. When pathologists do not understand what are the clinicians' reasonable demands, and when the clinicians have no knowledge of the difficulties of running a complex industrial concern which a modern laboratory is, then reams of paper sent down the "lines of communication" and hours of work on "coordinating committees" will not put the matter right.

Service in the Forces at least provided an older generation with some movement, some delay before specialization, some experience of a different system, and a yardstick of efficiency, but even that is denied those now rising through the training ranks. In 20 years' time few consultant pathologists will have had any significant direct responsibility for patients since full registration. Only the most able will manage to surmount this barrier when dealing with clinical colleagues, and pathology in general will have lost a body of experience that will take a generation to replace.

If communication between clinician and pathologist is not to break down entirely, this total re-orientation of training is going to be required. If properly carried out it will result in better recruitment into pathology (because who leaves medical school with a "vocation" for lab work?), a much better service will be provided, and in- cidentally the old bogey about pay scales will vanish because pathologists will be seen to be doctors first and lab men second.-I am, etc.,

JOHN HULBERT

Bacteriology Department, The University,
Dundee

JOHN HuLBer

\section{Medical Detainees in the Sudan}

SIR,-I have recently received disturbing news from medical sources in the Sudan concerning the conditions of imprisonment of Dr. Mustafa Khogali, president of the Sudan Medical Association, and three other medical colleagues, Dr. Tahir Abdel Rahman (a consultant surgeon, lately B.M.A. representative for the Sudan), Dr. Khalid Hassan Eltoum (a consultant radiotherapist, and secretary of the Sudan Medical Association), and Dr. Yahia Omer Hamza (a consultant paediatrician), who are known to many readers in this country and overseas.

The background to Dr. Khogali's case bears some elaboration. He obtained the D.T.P.H., D.I.H., and D.T.C.D. diplomas in Britain, completed his M.D. with commendation in 1969, and was later appointed head of the department of preventive medicine in Khartoum University. Last September he read the opening paper ${ }^{1}$ at the symposium on health problems of industrial progress in developing countries, held in London and attended by participants from 18 countries. $\mathrm{He}$ is an executive member of the All-Arab Medical Federation and is well known in Middle East medical circles.

On 1 June this year he was imprisoned, with some other lecturers at Khartoum University, without trial and without charges being brought, but was released on 21 July during the abortive coup. Two days later he was rearrested and sentenced by a military tribunal to 20 years' imprisonment with hard labour. Like other defendants in these trials, he was not allowed legal representation nor any right of appeal. The evidence on which he was convicted is not available, as the Sudan Government has refused to release any transcript of his trial.

It has taken some time for his friends in Britain to elucidate this minimum information. Dr. Khogali was not known in Britain for any strong political leaning or activity, and the news concerning him has bewildered and distressed many of his friends here, some of whom have addressed appeals for clemency to President Nemeiry. In the past few days I have learnt from two independent, reliable sources that Dr. Khogali has been subjected, with other political prisoners, to cruel physical maltreatment. Dr. Tahir Rahman, who was imprisoned without trial, has required hospital treatment for a medical condition exacerbated by his confinement.

May I appeal through your columns to other readers who feel concerned at this news to inform the Sudanese authorities of their views in order to achieve some amelioration of the harsh conditions of imprisonment of our colleagues, and perhaps a restoration of normal judicial processes and legal rights to enable a dispassionate review of their cases? - I am, etc.,

S. A. Hall 